\title{
Jerome Harold Kay (17 March 1921-14 August 2015): a great innovator in cardiac surgery
}

\author{
Yasunaru Kawashima ${ }^{1,2}$
}

Published online: 15 February 2016

(C) The Japanese Association for Thoracic Surgery 2016

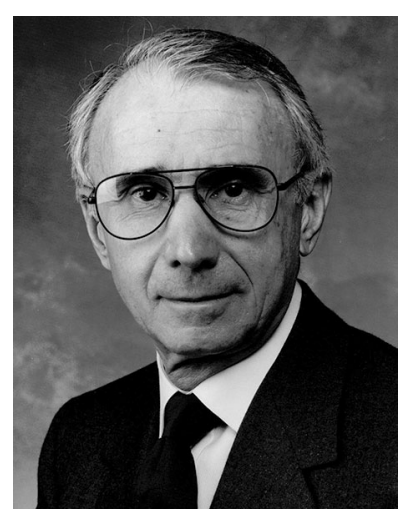

Jerome Harold Kay, the honorary member of the Japanese Association for Thoracic Surgery (JATS), was born on 17 March 1921, in Aiken, Minnesota, USA. He received his Doctor of Medicine degree from University of California San Francisco, San Francisco California in 1945. After his General Surgery internship and residency training, he did research and additional residency training in General Surgery, Thoracic, and Cardiac Surgery at the Johns Hopkins Hospital, Baltimore, Maryland from 1950 to 1954. From 1954 through 1956, Dr. Kay did clinical and experimental work at the National Heart Institute in Bethesda, MD.

Dr. Kay became Associate Professor of Cardiac Surgery at the University of Southern California and Chief of Thoracic and Cardiac Surgery at Los Angeles County-USC

Yasunaru Kawashima

ykawashi@mgt.ncvc.go.jp

1 National Cerebral and Cardiovascular Center, Fujishiro-dai 5-7-1, Suita, Osaka 565-8565, Japan

2 Department of Surgery, Osaka University School of Medicine, Yamadaoka 2-15, Suita, Osaka 565-0871, Japan

Medical Center in 1956. His private practice of the Kay Medical Group was also started at St. Vincent's Hospital, Los Angeles and then moved to Good Samaritan Hospital, Los Angeles, California in 1986.

During 36 years between June 1963 when Dr. T. Yamada landed at Los Angeles International Airport, and September 1999 when Dr. S. Tokunaga left there, 52 young Japanese surgeons had been trained at St. Vincent Hospital, Good Samaritan Hospital and the Laboratory of University of Southern California School of Medicine by Dr. Kay and his associates. After coming back to Japan they contributed to the development and advancement of cardiac surgery in Japan and 13 among them have gone on to the professor of surgery throughout Japan.

Dr. Kay is well known for his many pioneering works particularly in valve surgery. Kay's annuloplasty techniques in mitral [1] and tricuspid valves [2] are almost exclusively performed for a while in Japan as his disciples propagated the Kay's technique in all over Japan before mitral and tricuspid valve rings become popular in this country.

In addition to this, Dr. Kay developed so-called "KayShiley disc valve" in 1964. This valve was initially implanted experimentally in the mitral position of dogs by Drs. Kawashima and Kagawa from Japan at the laboratory of the University of Southern California [3] and started to be used clinically in 1965 [4] in Los Angeles and 1966 in Osaka.

Although Dr. Kay's contributions in valvular surgery were well known, he was also the first to remove a myxoma in the left ventricle [5] and the first to cure the patient with candida albicans endocarditis surgically [6].

Not only in adult cardiac surgery but also in congenital cardiac surgery, he was ahead of his time. For example, Dr. Kay was the first to report trans-right atrial closure of VSD 


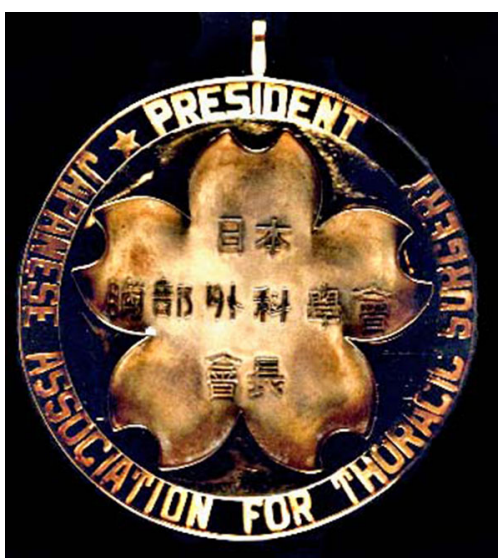

Fig. 1 JATS Presidential Medallion donated by Dr. JH Kay

in US [7]. Dr. Kay reported it at the twenty-first annual meeting of the Society of University Surgeons in 1960. Dr. C. Walton Lillehei discussed this paper saying that the view through tricuspid valve was not satisfactory, so that the use of this method is limited. At present, however, it is a world standard to close VSD via the right atrium through the tricuspid valve.

Dr. Kay was invited to Japan for the first time in 1975 by Dr. Manabe to deliver the lecture entitled "Surgery for Coronary Artery Disease" [8] at the 28th Annual Meeting of the Japanese Association for Thoracic Surgery (JATS). Unforgettable affair for the Association is that Dr. Kay donated a Presidential Medallion of JATS (Fig. 1) to the association. Since then, it had been succeeded year by year to the new president for these 40 years. The association installed him to the honorary member at the 42nd annual meeting held in Osaka 1989.
Jerome Harold Kay, who gave a great influence to the cardiac surgery in Japan, died on 14 August 2015 in Los Angeles. At the General Assembly of JATS meeting in 2015, members kept silence for him and Dr. Kay's medallion was handed over to Dr. Miyoshi, the next president, by President Dr. Okita. Thus the name of Jerome Harold Kay will be transmitted among the Japanese cardiac surgeons as far as JATS exist.

\section{References}

1. Kay JH, Egerton WS, Zubiate P. The surgical treatment of mitral insufficiency and combined mitral stenosis and insufficiency with use of the heart-lung machine. Surgery. 1961;50:67-74.

2. Kay JH, Maselli-Campagna G, Tsuji HK. Surgical treatment of tricuspid insufficiency. Ann Surg. 1965;162:53-8.

3. Kay JH, Kawashima Y, Kagawa Y, Tsuji HK, Redington JV. Experimental mitral valve replacement with a new disc valve. Ann Thorac Surg. 1966;2:485-97.

4. Kay JH, Tsuji HK, Redington JV, Kawashima Y, Kagawa Y, Yamada T, Caponegro P, Mendez A. Clinical use of a new mitral disc valve. Calif Med. 1967;106:165-9.

5. Kay JH, Anderson RM, Meihaus J, Lewis R, Magidson O, Bernstein S, Griffith GC. Surgical removal of an intracavitary left ventricular myxoma. Circulation. 1959;20:881-6.

6. Kay JH, Bernstein S, Feinstein D, Biddle M. Surgical cure of candida albicans endocarditis with open-heart surgery. N Eng J Med. 1961;264:907-10.

7. Kay JH, Anderson RM, Tolentino P, Dykstra P, Shapiro MJ, Meihaus JE, Magidson O. The surgical repair of high pressure ventricular septal defect through the right atrium. Surgery. 1960;48:65-75.

8. Kay JH. The current status of surgery for coronary artery disease. J Jpn Ass Thorac Surg. 1976;24:351-69. 